\title{
TRICHOMONAS VAGINALIS INFECTION AMONG STUDENTS OF UNIVERSITY OF PORT HARCOURT
}

\author{
Eze Chinwe $\mathbf{N}^{1 *}$, Edwin Queen Okwuchi ${ }^{2}$ \\ *1,2Department of Animal and Environmental Biology, University of Port Harcourt, P.M.B.5323, Choba, Rivers State, \\ Nigeria.
}

*Corresponding Author: -

EmailID - chinwe.eze@uniport.edu.ng

\begin{abstract}
: -
Trichomonas vaginalis is one of the most common curable sexually transmitted disease. Untreated Trichomoniasis in women can cause cervicitis, vaginites and pelvic inflammatory disease. Trichomonas vaginalisis contributes to high risk of cervical cancer in women and HIV in men. This is an institutional based cross-sectional descriptive study conducted among two hundred (200) female students of Delta Hostels, University of Port Harcourt. High vaginal swabs (HVS) and urine samples were collected from consented students and examined for the presence of $T$. vaginalis under the microscope. A total of 32(16\%) were infected and results obtained from HVS showed a prevalence of 32\% compared to urine microscopy which no positive sample was detected. Students between the age group 1525yrs had the highest prevalence of infection 31(17.2\%) while the age group 26-35 years had 1(5\%). However, the difference was statistically significant. Based on marital status all were single and had 32(16\%) prevalence. This study observed a high prevalence of T. Vaginalis and its symptoms among the study population. The study also noted that high vaginal swab microscopy showed better detection sensitivity compared to urine microscopy. The best option for prevention and control is to educate students on personal hygiene and safe sex practice.
\end{abstract}

Keywords: - Current, Prevalence, Trichomonas vaginalis, Females, Hostels, University of Port Harcourt.

\section{(c) $(\$)$}




\section{INTRODUCTION}

Trichomonas vaginalis is one of the most common curable sexually transmitted disease known as trichomoniasis (Kim et al., 2017). Untreated TRICHOMAONIASIS in women can cause cervicitis, vaginites and pelvic inflammatory disease (Marrazo and Martin, 2007; Jahic et al., 2013). Trichomonas vaginalisis was reported to contribute to high risk of cervical cancer in women and HIV in men (Jahic et al., 2013). Female sex workers have been reported to increase the spread of Trichomonas vaginalis and other sexually transmitted infections to the general public, so treating this group can aid in the control of this disease (Shrestha et al., 2016). In infected females, Trichomonas vaginalis can cause green-yellowish vaginal discharge, irritation of the vulva, itching, pain during urination, hemorrhagic lesion of the cervix. According to World Health Organization (WHO), an estimated 174 million cases of Trichomoniasis are reported annually and this account for about 10-25\% of vaginal infections (Poole and Mcclelland, 2013). There have been several reports from various parts of Nigeria on Trichomonas vaginalisis including those of Usanga, 2009 who documented evidence of Trichononiasis among pregnant women in Calabar with a prevalence of 5.2\%. It was observed to be a public health problem in Onitsha as $17.5 \%$ was recorded among women attending health center in Onitsha Anambra State (Iwueze et al., 2014). However, Wokem and Ndokwu (2014) declared that $T$. vaginalis infection was on the increase after recording $10 \%$ prevalence in the evaluation of the vulvo-vaginal Trichomoniasis among women in Niger Delta region of Nigeria. Trichomoniasis vaginalis is prevalent and should not be ignored (Bowden and Garneth, 1999). There is need therefore to know the prevalence and distribution of the disease among students. However, there is no report on the prevalence of Trichomonas vaginalis infection among females living in the hostels in the University of Port Harcourt.

\section{Material and Methods \\ Study Area}

The cross sectional descriptive study was carried out in the University of Port Harcourt, Choba community in Obio-Akpor Local Government Area of Rivers State. It is located between N4 52 ' 30' and N4 $55^{\circ}$ '00' ' and E6 6 54'49' '\& E 6 54 '49'. The thick mangrove forest, raffia palm and light rainforest are the major type of vegetation. Due to high rain fall, the soil in the area is usually sandy or sandy-loam. It is always leached, underlain by a layer of impervious pan. The University of Port Harcourt has over 40,000 students in attendance with an average of 6000 students every year. And of this about $67 \%$ are female students (anonymous, 2017).

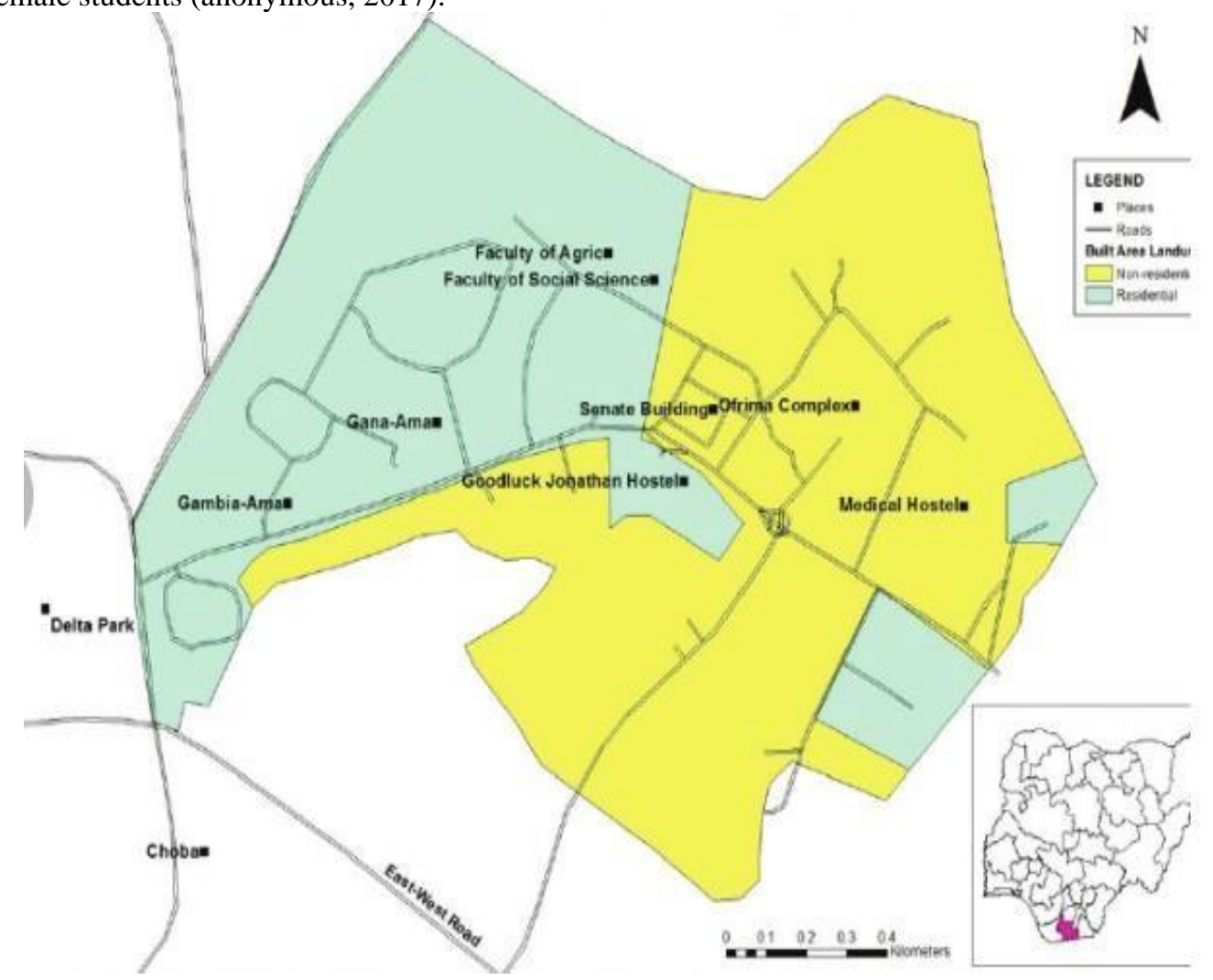

Fig. 1. The study area University of Port Harcourt.

\section{Study population}

A total of two hundred and thirty students were recruited for this study, the study population consisted of students living in Delta hostels in university of Port Harcourt. However, only 200 returned their urine bottle and were examined. Informed consent was sought from the participants before specimen collection serial sampling was employed and students who did not return their consent forms were excluded from the study. Also, ethical clearance was gotten from the hall warden of King Jaja hostels (Block A and C) and the students were sensitized on the nature of the test to be carried out.. 


\section{Sample collection and Parasitological Analysis}

Specimen collection and examination of urine and High vagina swab (HVS) were aseptically performed following the standard procedure. Also, microbiological investigation of macroscopy and microscopy were immediately evaluated to avoid loss of characteristic tumbling motility of the organism and death that may follow due to loss of moisture.

\section{Sample collection.}

Early morning urine and vaginal swab samples were collected from the students aged 15-45 years. A total of 200 urine samples and 200 vaginal swabs were collected from the students. Also, structured questionnaire was administered to obtain demographic characteristics of the students - age, marital status, and use of toilet system, sharing of under wears or towels and symptoms. Urine samples were collected using factory sterilized (Stermacon) plastic sterile bottles while vaginal swabs were collected using sterile Evepon swab sticks. The samples were brought to the Parasitology Laboratory, University of Port Harcourt and analysed within 3 hours of collection

\section{Examination of Urine Samples}

About $1 \mathrm{ml}$ of each urine sample was poured into a centrifuge tube and spun at 3,500 rpm for 5 minutes. The supernatant fluid was decanted and a drop of the sediment was placed on grease free glass slide, covered with a coverslip and examined microscopically for Trichomonas vaginalis

\section{Examination of Vaginal Swab Samples}

A drop of normal saline was introduced into the pack of each respondent's vaginal swab and mixed by shaking vigorously to wet the swab. A drop of the mixture of each sample was placed on clean grease-free slide, covered with coverslip and examined microscopically using $x 10$ and $\times 40$ objectives with condenser iris sufficiently to observe motile flagellated form of $T$. vaginalis

\section{Statistical analysis}

The data obtained from questionnaires and laboratory analysis were analysed statistically using Chi-square with significant difference set at $5 \%$ level

\section{Results}

Although 230 female students of University of Port Harcourt, Rivers State were initially enrolled for the study, only 200 students submitted urine and swab samples and were included in the data analysis. The findings of the study revealed that $32(16.0 \%)$ out of 200 students examined, were infected with trichomoniasis. Thirty two (16.0\%) students had Trichomonas vaginalis in their vaginal swabs but none was found in their urine samples. Students between the age group 15-25 had the highest prevalence of T.vaginalis 31(17.2\%) while age group of 26-35 had prevalence of 1(5\%). Based on marital status all were single and had 32(16\%) prevalence for the infection Table 1 . The difference in the prevalence of infection between the different age-groups was statistically significant $(\mathrm{p}<0.05)$. Prevalence of trichomoniasis based on clinical manifestation and risk factors revealed that $20(10 \%)$ of the students had vaginal discharges and $5 \%$ had itching/irritation Table 2. However, infection was highest 27(13.5\%) among the students who used the general school toilet as well as those who shares wears $22(11.0 \%)$.

Table 1: Distribution of Trichomonas vaginalis among students by sampling method

\begin{tabular}{llllll}
\hline Variables & Classification & $\begin{array}{l}\text { Number } \\
\text { Examined }\end{array}$ & $\begin{array}{l}\text { Number } \\
\text { Infected }\end{array}$ & $\begin{array}{l}\text { Percent } \\
\text { Infected (\%) }\end{array}$ & p-value \\
\hline Specimen & Swab & 200 & 32 & 16 & 0.06 \\
& Urine & 200 & 0 & 0 & \\
Age (years) & 15-25years & 180 & 31 & 17.2 & 0.08 \\
& 26-35 years & 20 & 1 & 5.0 & \\
& 36-45 years & 0 & 0 & & 0.06 \\
Marital Status & Single & 200 & 32 & 16 & \\
& Married & 0 & 0 & 0 &
\end{tabular}




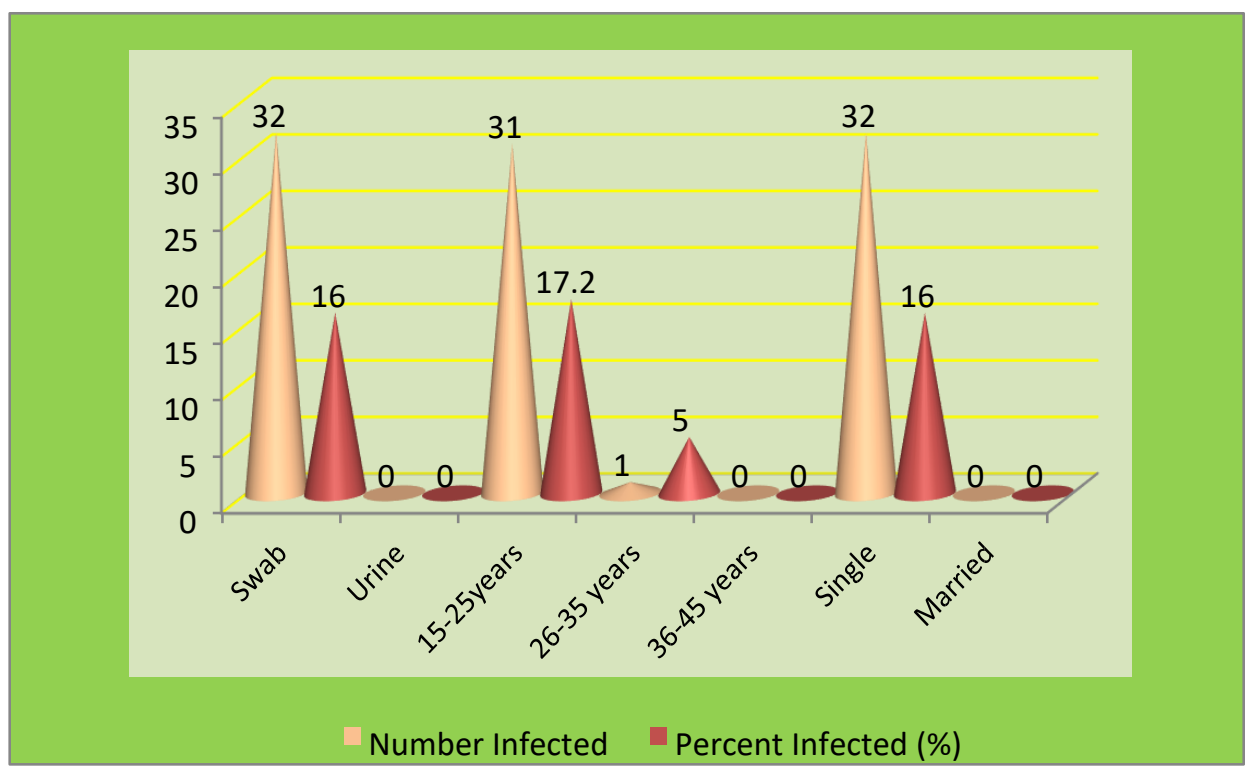

Figure 1: Distribution of T. vaginalis

Table 3: Distribution of Trichomonas vaginalis among Infected Students by Clinical Manifestation and Risk Factors

\begin{tabular}{|c|c|c|c|c|}
\hline Variables & Classification & $\begin{array}{l}\text { Number } \\
\text { Infected }\end{array}$ & $\begin{array}{c}\text { Percent } \\
\text { Infected (\%) }\end{array}$ & p-value \\
\hline \multirow[t]{3}{*}{ Symptoms } & Vaginal Discharge & 20 & 10 & 0.01 \\
\hline & Dysuria & 2 & 1 & \\
\hline & Itching/irritation & 10 & 5 & \\
\hline \multirow[t]{2}{*}{ Toilet system } & $\begin{array}{l}\text { General School } \\
\text { Toilet }\end{array}$ & 27 & 13.5 & \\
\hline & Personal Bucket & 5 & 2.5 & \\
\hline \multirow[t]{2}{*}{ Sharing of Wears } & Yes & 22 & 11 & 0.09 \\
\hline & No & 10 & 5 & \\
\hline
\end{tabular}

\section{Discussion}

Most previous studies on Trichomonas vaginalis in this geographical region have focused on transmission patterns of the disease in pregnant women and rural populations. The present investigation was one of the first institutional- based studies on prevalence of $T$. vaginalis in Rivers State. The findings of this study show that trichomoniasis is prevalent in the University of Port Harcourt though no previous data on the prevalence in the university exists. The overall prevalence recorded in this study is high when compared to the previous report of Abah (2017) who recorded a low rate of $(0.63 \%)$ in Rivers State, Usanga et al., (2009) recorded (5.2\%) among pregnant women in Calabar and Wokem (2006) also recorded $10 \%$ prevalence among women in Niger Delta region. This value $(16.0 \%)$ is lower than the observations of 44.23\% made by Ito and Nmor (2018) among women in Isoko South, Delta State. Crucitti et al. (2010) recorded a prevalence of $28 \%$ in Monglia although it was among sex workers. However, $32(16.0 \%)$ recorded in this study is similar to the report of Iwueze et al. (2014) who recorded a prevalence of (17.5\%) among women in Onisha, Anambara State and $15.0 \%$ by Onyido et al., (2014). It appears that Trichomonas vaginalis is particularly common among students, especially as the prevalence recorded in the present study was probably an under-estimate of the true value, given that it was based on the results of the examination of just on urine and smears of vaginal swabs /student. Trichomoniasis is the most prevalent sexually transmitted parasitic infection, yet it appears to be highly neglected in the higher institutions and adequate attention has not been given to its control and eradication. The differences in values recorded by other works and this study could be due to the lifestyle of the students examined, geographical location and communal use of school toilets. The non-detection of parasites in urine samples and a detection rate of 32(16\%) from direct wet smears of vaginal swab samples as obtained in this study disagreed with the findings of Dahab et.al, (2012) who reported highest and all prevalence rates from urine samples in a survey in Sudan. Findings of previous work revealed that the microscopic examination of direct wet smears of vaginal swabs had higher prevalence of trichomoniasis than examination of urine deposits (Usanga et al., 2009; Ito and Nmor, 2018). Therefore direct wet smear of vaginal swabs should be considered a better diagnostic approach than urine deposits examination. Though collection and processing of urine is more cost effective than high vaginal swab but the use of high vaginal swab makes it easier for researchers to screen subjects with accurate results. In the present study, higher prevalence of infection was observed amongst 15-25yrs students, only one student among the age bracket 26-35yrs was recorded. Similar trends have been recorded before in Nigeria and elsewhere in Africa (Decastero, 1989; Usenga et al., 2006; Jautau et al., 2006, Dahab et.al, 2012; Ito and Nmor, 2018). Who reported 
that trichomoniasis is more prevalent amongst the more sexually active young people. It could also be that younger females have more sexual partners than the older ones. On the contrary, results by Iwueze et al., 2014; Inan et al., 2010 reported prevalence of Trichomonas vaginalis to be higher among women in the age group 30-39. This study also showed that infection were significantly higher in singles than married women $(\mathrm{p}<0.05)$. It was revealed that all the infested participants in this study were all singles. Hence, single women/students should avoid having casual sex with unknown sex partners. Furthermore, majority of the students reported of vaginal discharge and irritation or itching, this varied with the result of Ojurongbe et al. (2010). Besides being transmitted sexually, there have been cases of nonsexual transmission of Trichomoniasis such as contaminated towels, wears, douche nozzles, toilet seats, or swimming pool water. It was observed that; students using general toilet were more exposed to the infectious agent than students using personal bucket system. The unhygienic and deplorable conditions of toilet school hostels without proper maintenance may have contributed to the high prevalence and spread of this infection among students as well as sharing of wears like towel and under wears.

\section{Conclusion}

This study revealed a high prevalence of $T$. Vaginalis and its symptoms among the female student in university of Port Harcourt, River State, Nigeria. The study also noted that high vaginal swab microscopy showed better detection compared to urine microscopy. The best option for prevention and control is to educate the students on personal hygiene and safe sex practice.

\section{References}

[1].Abah, A. E. (2017). TrichononasVaginalis Infection in a Typical Urban and Suburban Area of Rivers State, Nigeria. Asian Journal of Medicine and Health; 6 (4): 1-6.

[2].Amadi, A. N. C and Nwagbo, A. K (2013). Trichomonas vaginalis infection among women in Ikwuano Abia state. J. Applied science col. 17(3) 389-393.

[3].Bowden J. Francis and Geofrey P. Garnett (2000). Trichomonas vaginalis epidemiology; parameterising and analyzing a model of treatment intervention sexual transmitted infections. 76(4) 248-256.

[4].Crucitti T, Jespers V, Mulenga C, Khodowes and Vandepitte J, (2010). Trichomonas vaginalis is highly prevalent in adolescent girls, pregnant women and commercial sex workers in Ndola Zambia. Public libratory science; Sexual transmitted diseases; 37; 223-227.

[5].Cudmore, S. I. Delgaty, K. L.,Hayward-Mcclelland, Petrin, D. P. and Garber, G. F. (2004).Treatment of Infections Caused by Metronidazole- Resistant T. vaginalis. Clinical Microbiology Review; 17:783-793.

[6].Dahab, M.M, Koko, W.S., Osman, E.E. and Hilali, A.H.M (2012). Prevalence and Transmission of Trichomonas Vaginalis Infection among Women in Khartoum State, Sudan. Journal of Public Health and parasitolology; 4(2): 34-38.

[7].Dennerstein.L, Lehert P., Burger H and Gutheriey (2005). Sexuality. American journal of medicine.118 (12B) 59-63.

[8].Iwueze, M. O., Ezeanyanwu, L. N., Okafor, F. C., Nwaorgu, O. C., Ukibe, S. C. (2014). Prevalence of TrichononasVaginalis Infection among Women Attending Hospitals/Health Centres in Onitsha Community, Onitsha North Local Government Area of Anambra State. The Bioscientist; 2(1): 54-64.

[9].Jamic, Mahira, Mulavdic, Mirsada, Jasmina; Jahia, Elmir and Nurkic Midnat (2013). Pathogen Trichomonas Vaginalis. ScienceGove. 2013-01-01.

[10]. Jatau ED, Olonitola OS and Olayinka .(2006) . Prevalence of Trichomonas Infection among Women Attending Antenatal Clinics in Zaria, Nigeria. Annals of African Medicine; 5(4):1 78-18.

[11]. Kim Jung-Hyun and Ik-HwanHan (2017). Interaction between TrichomonasVaginalis and the Prostate Epithelium the Korean Journal of Parasitology.

[12]. Kissinger Patricia (2015). Epidemiology and Treatment of Trichomonas Vaginalis. Journal; Current Infectious Disease Reports; 17 (6): 484.

[13]. MarrazzoJ. M and Martins DH (2007)Vulvo-vagina candidiasis. British medicine Journal 325; 582-87.

[14]. Olorode, O.A., Ogba, O.M., and Ezenobi, N. (2014).Urogenital Trichomoniasis in Women in "Relation to Candidiasis and Gonorrhoea in University Of Port Harcourt Teaching Hospital. African Journal of Microbiology Research; 8(26):2482-2485.

[15]. Ojurongbe Olusola, Taiwo Bolaji O, Dina Babatunde O, Sina-Agbaje Olawunmi R, Bolaji Oloyede S and Adeyeba Adegboyega. 2010 Prevalence of Trichomonas vaginalis Infection among Pregnant Women in Abeokuta, Nigeria. Sierra Leone J Biomed Res. Vol. 2 No. 2

[16]. Onyido AE, Umeanaeto PU, Irikannu KC, Ekwunife CA, Ezeanya LC, Nwangwu UC, Ugha CN, Obiechina IO. (2014). Prevalence Trichomonas vaginalis among the rural women of Ekwulumili community Anambra State, Southeastern Nigeria. Natural Science 12(5):129134.

[17]. Poole Daniel N. and Scott Mcclelland (2013). Global Epidemiology of TrichomonasVaginales.

[18]. Shrestha, TC Harry and S Rahid (2016). Ignored Trichmomonal Infestation Diagnosed By Dapaniceleous Smear. TlK Genitourinar Medicine.

[19]. Uneke, C. J., Cletus, D.C., Ugwuoru, E.A. \& Mirian , A. (2006). Trichomonas vaginalis infection among pregnant women in South-Eastern Nigeria: Public health significance. The Internet Journal of Gynaecology and Obstetrics. 6 (1): 1528-1540

[20]. Usanga, V., Abia-Bassey, L., Lnyang-Etoh, P., Udoh, S., Ani, F., and Archibong E. (2009).Trichomonas vaginalis infection among pregnant women in Calabar, Cross Rivers State, Nigeria. The Inter J Gynecol Obst, 14(2) 
[21]. Wokem, G. N., (2006). TrichomonasVaginalis Infection in Some Parts of Niger Delta Region, Rivers State, Nigeria. Nigerian Journal of Parasitology. 27:68-72.

[22]. Wokem, GN, and Ndukwu, CB (2015). Re-Evaluation of Vulvo vaginal trichomoniasis among Women in Niger Delta Region, Nigeria. Global Journal of Pure and Applied Sciences; 21(1):13-19. 